\title{
Deforestation in Africa-Steps Towards a Solution?
}

Deforestation and the shortage of wood in a large number of Third World countries are assuming tragic dimensions. In Africa, wood provides $60 \%$ of the energy used (up to $90 \%$ in some of the least developed countries) and at the present rising rate of consumption, wood is no longer a renewable source of energy.

These facts and the relevant figures have been repeated in articles, commentaries, reports, and debates, until they have now become common knowledge. A multitude of recommendations have been put forward, but the extent to which these are implemented is still very limited. However, increasing awareness of the problem has led a number of governmental and non-governmental agencies to attempt to counteract the present situation. One of these agencies is Le Comité Européen d'Aide aux Réfugiés (CEAR).

CEAR is a small, primarily French non-governmental organization that was created in 1980 by a group of people who had been moved by the plight of refugees in South-East Asia. The purpose of this agency is to send in its teams (made up of Europeans, local people, and refugees themselves) to help people after an emergency, when the problems of sheer survival and urgent medical treatment have been solved. The refugees then find themselves in a state of extreme dependence, condemned to inactivity and uncertainty about the future. In Thailand, Somalia, and also Sudan, CEAR concentrates on the task of reintegrating these refugees into society, helping them-through training and work in agriculture, appropriate technology, and simple know-how - to become once more a productive and self-supporting group.

CEAR first became involved in energy conservation in the refugee camps of Somalia in 1982, and more recently in the Eastern Region of Sudan. The devastating effects of deforestation, compounded by the settlement of some 400.000 refugees from Ethiopia in Sudan and some 700,000 in Somalia (thus increasing the demand for wood as fuel and building materials) have forced back the boundaries of the once abundant forests. Although attemps are being made, particularly in Sudan, to replant deforested areas with nursery seedlings, the demand for wood persists and widely intensifies.

In Somalia, studies were carried out to design and manufacture a small earthenware fuel-saving stove which economizes up to $50 \%$ of the energy consumed by the traditional open stove. A low-cost and efficient model has been developed (Fig. 1), but the most difficult part of this project is to persuade the refugees actually to use it.

A small brick-producing unit has recently been set up to meet the increasing demand for building materials in the area. The fact that more and more public-utility buildings will now be built with bricks, will substantially reduce the use of wood as a construction material.

CEAR's most important energy conservation project has recently got under way in Sudan. The programme, implemented through the Sudanese Government Commissioner's Office for Refugees, and with the assistance of the United Nations High Commission for Refugees, aims to improve the level of economic self-sufficiency of refugee and Sudanese participants. Income can be generated by the manufacture and sale of building materials other than wood, and of fuel briquettes made from agro-industrial waste products such as peanut shells, cotton stalks, bagasse, molasses, and charcoal dust. The manufacturing technique involves the use of several small and simple, manually-operated pressing machines.

As an integral part of this programme, CEAR volunteers will be demonstrating improved techniques of construction

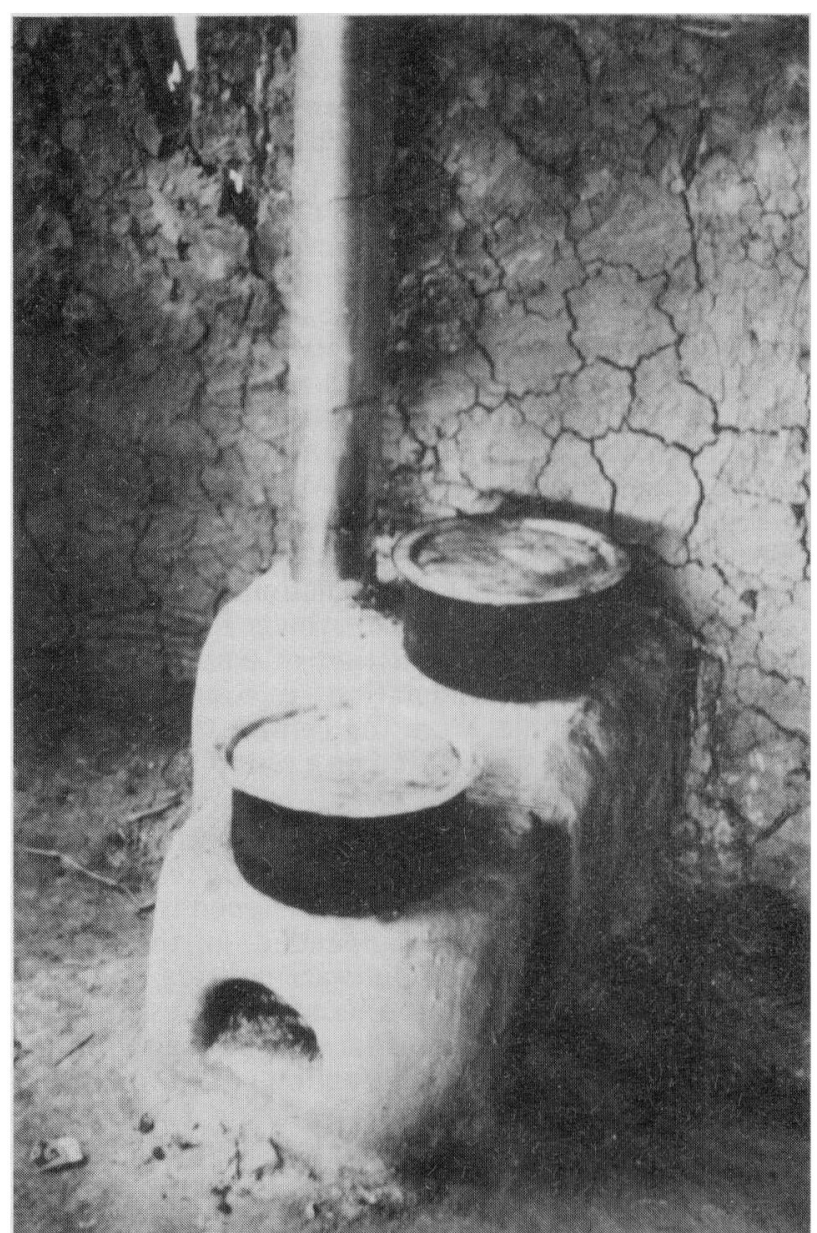

FiG. 1. This earthenware stove is one of the more elaborate (yet very economical) stoves designed by CEAR technicians.

which emphasize 'low-cost' utilization of raw materials, and, above all, the conservative use of wood.

Complementary to this, a training centre is planned to give instruction to the local Sudanese and refugee community on various aspects of wood-fuel conservation. This should include the identification of alternative fuel sources and their adaptation for use; methods of reducing domestic and industrial consumption of wood-derived fuels; techniques of tree cultivation and protection, and so on.

These efforts are examples of small-scale, low-cost projects that are being set up to counteract the rapid deforestation of certain areas, and from which tangible results may be expected to appear soon. However, although these isolated measures may be effective, solutions which match the size of the present problem will be found only when concerted large-scale efforts are made, and when financial, human, and material, resources are combined to work efficiently towards solving what is often thought of as an irreversible situation.

\section{HELEN ALDERSON Comité Européen d'Aide aux Réfugiés 3 Avenue Bertie-Albrecht 75008 Paris \\ France}

